\title{
Effects of Biotin and Folic Acid on Motility, Viability, Morphology, Chromatin Density and Integrity of Cryopreserved and Thawed Sperm in Normozoospermic Men
}

\author{
Reyhaneh Montazari ${ }^{1}$, Farhad Golshan-Iranpour. ${ }^{2,6}$, Gholam Reza Dashti: ${ }^{3,6}$, Shahla Ishaqi ${ }^{4,6}$, Abol fazl \\ dashti. ${ }^{5}$ \\ 1. Medical doctor, Department of Anatomical Sciences, School of Medicine, Isfahan University of Medical Sciences, \\ Isfahan, Iran. ORCID ID: 0000-0001-5414-6118. \\ 2. Associate Professor, Department of Anatomical Sciences, School of Medicine, Isfahan University of Medical Sciences, \\ Isfahan, Iran. ORCID ID: 0000-0002-2725-6423. \\ 3.Professor, Department of Anatomical Sciences, School of Medicine, Isfahan University of Medical Sciences, Isfahan, Iran. \\ (Corresponding Author) Email: dashti@mui.ac.ir, Tel: 03137929040, ORCID ID: 0000-0003-3390-3233. \\ 4. Laboratory Technician, Shahid behesti hospital, Isfahan University of Medical Sciences, Isfahan, Iran. ORCID ID: 0000- \\ 0001-9181--8761. \\ 5. Doctor of Veterinary Medicine,School of Veterinary Medicine, Azad University of Shahrekord, Shahrekord, Iran. ORCID \\ ID: 0000-0001-8088-2020. \\ 6. Saint Maryam Fertility and Infertility center, Shahid beheshti hospital, Isfahan, Iran.
}

\begin{abstract}
Background and aim: Cryopreservation is one of the common techniques in the management of infertility, which can damage the sperm cell and its function by producing reactive oxygen species. To determine health and fertility of cryopreserved sperm, we evaluated different markers in infertile men. The aim of this study was to investigate the effect of biotin and folic acid on motility, viablity, shape, chromatin density and membrane integrity of cryopreserved and thawed sperm in normozoospermic men.

Materials and Method: In this experimental study, 30 samples were collected from normozoospermic men. Every sample included fresh pre-cryopreservation group, cryopreserved control groups, biotin $(10 \mathrm{mM})$, folic acid $(50 \mathrm{nM})$, and combination of biotin $(10 \mathrm{mM})$ and folic acid $(50 \mathrm{nM})$ groups. Sperms were frozen for two weeks using the usual freezing technique at $196^{\circ} \mathrm{C}$ and then thawed. Samples were evaluated for motility before and after freezing using computer-aided sperm analysis software. We assessed sperm viability by eosin-negrosin staining, chromatin density by toluidine blue staining and membrane integrity by hypo osmotic swelling test.
\end{abstract}

Results: Before cryopreservation, motility, viability, chromatin density, sperm membrane integrity were higher and the number of immotile sperms were lower in all groups $(p<0.001)$. Quality of chromatin was higher in the groups of folic acid, biotin + folic acid and biotin than in the control group. Mean sperm viability was higher in the three above mentioned groups than in the control group. We found higher sperm membrane integrity in the folic acid, biotin and combination groups than in control group ( $\mathrm{p}<0.001$ ). After cryopreservation, a positive correlation was found between sperm chromatin quality and membrane integrity.

Conclusion: Biotin and folic acid showed a protective effects on chromatin quality, membrane integrity, viability of the sperms and played an important role in maintaining sperm parameters after cryopreservation.

Keywords: Biotin, Folic acid, Chromatin, Viability, Sperm, Cryopreservation. Received: May 22, 2019 Accepted: April 27, 2021

How to cite the article: Reyhaneh Montazari, Farhad Golshan-Iranpour, Gholam Reza Dashti, Shahla Ishaqi, Abol fazl dashti. Effects of biotin and folic acid on motility, viability, morphology, chromatin density and integrity of cryopreserved and thawed sperm in normozoospermic men. SJKU 2021;26(4):38-49.

Copyright (C) 2018 the Author (s). Published by Kurdistan University of Medical Sciences. This is an open access article distributed under the terms of the Creative Commons Attribution-Non Commercial License 4.0 (CCBYNC), where it is permissible to download, share, remix, transform, and buildup the work provided it is properly cited. The work cannot be used commercially without permission from the journal 


\section{بررسى تأثير بيوتين و اسيدفوليك بر حركت، حيات، شكل، تراكم كروماتين و تماميت غشا

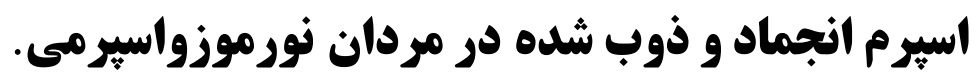

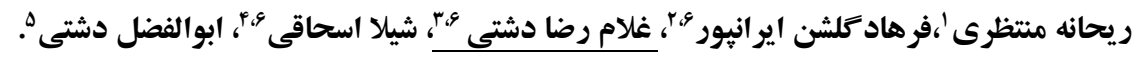

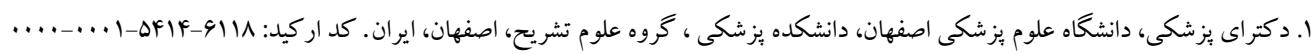

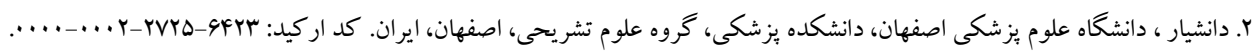

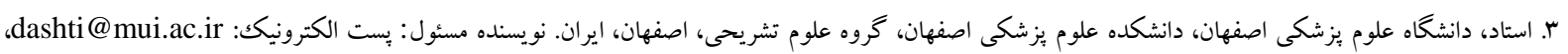

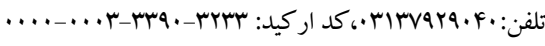

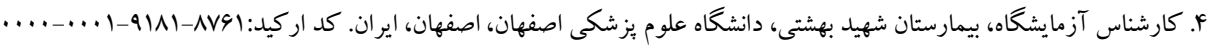

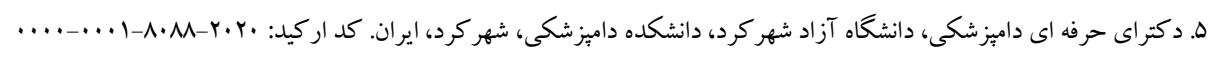

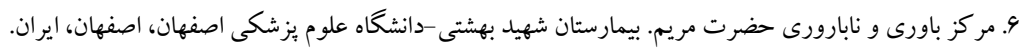

\section{جָكيله}

زمينه و هدف: انجماد يكى از تكنيكى رايج در بارورى-نابارورى است، با توليد راديكالهاى فعال اكسيزن موجب آسيب سلول

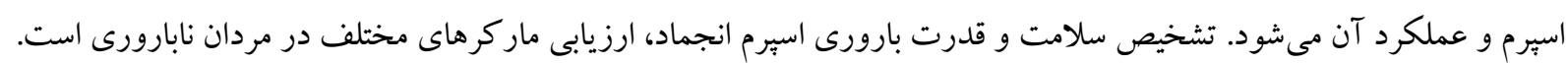

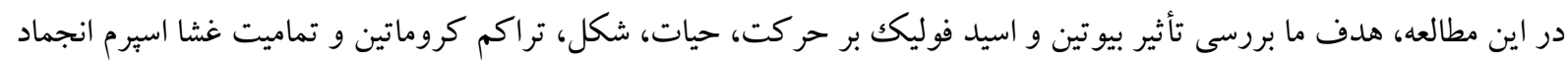
و ذوب شده در مردان نورموزواسبرمى است.

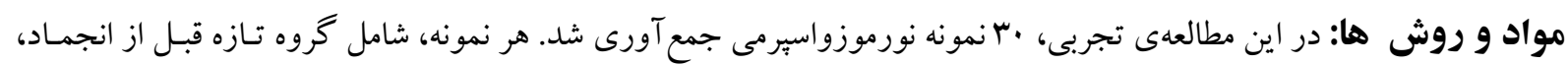

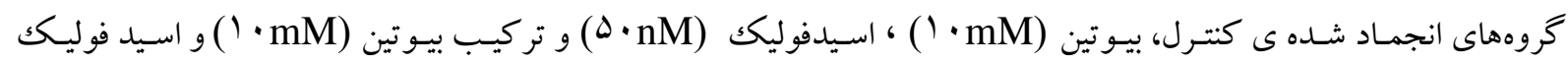
قا

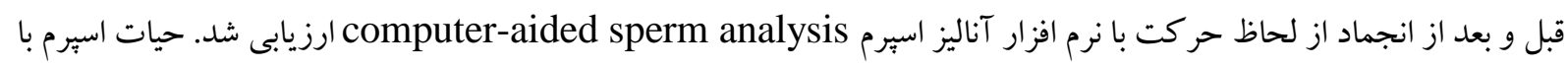

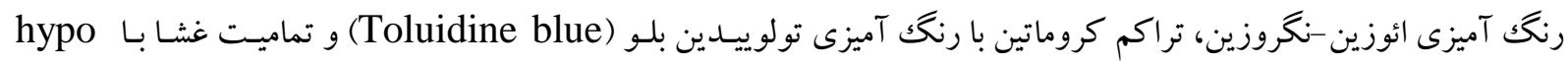
Osmotic swelling Test

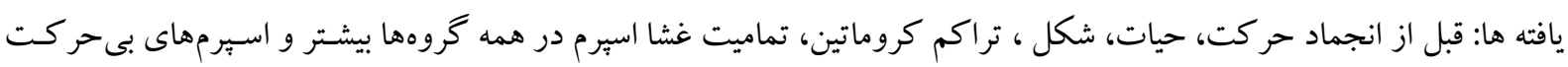

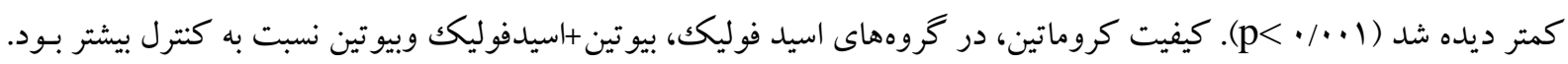

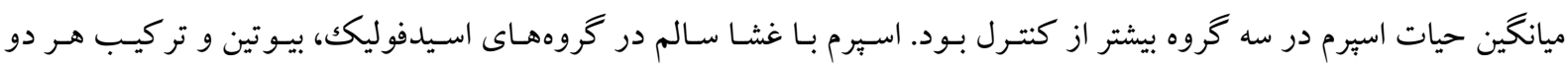

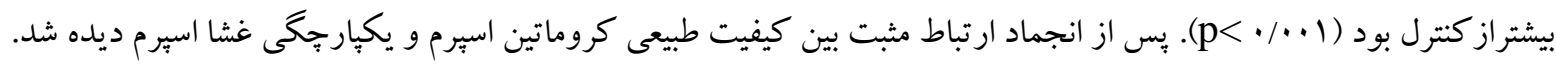

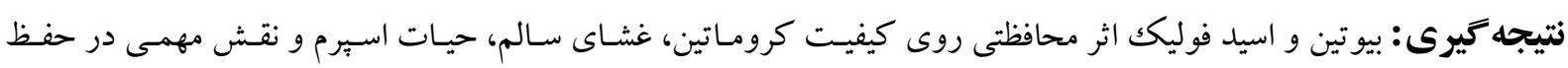
يارامترهاى اسيرم بعد از انجماد داشت. وازههاى كليدى: بيو تين، اسيد فوليك، كروماتين، حيات، اسبرم، انجماد.

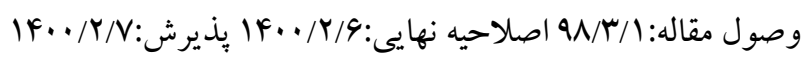


مى شود و بـا استفاده از آنتى اكسيدان مىتوان تـا حـدودى تعادل حفظ كرد(با). مصرف ويتامين E بـه عنوان آنتى

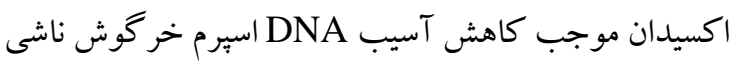
از مصرف غذاهاى ير كلسترول و آهن مى شود(F) (1). ويتامين

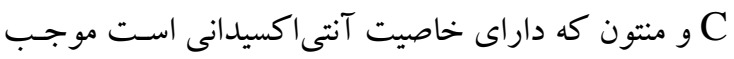
كاهش آسيب DNA اسبرم و حمايت از سلول هـاى اسـبرم در برابر آيويتوز در مقابل اثر سيتو تو كسى آسيكلووير مسى ونى

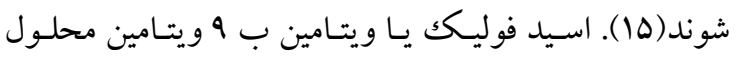

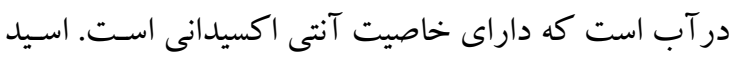
فوليكك فرم سنتيكك وصسناعى ايسن ويتـامين مس باشــ (19).

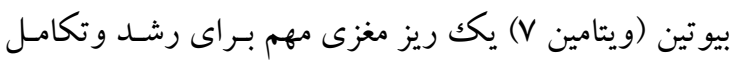

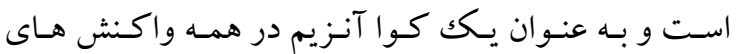
كربو كسيلاسيون درساخت اسـيدهاى جـرب، كلو كونؤُخنز؛

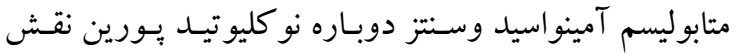
دارد. مطالعات ثابت كرده اند كـه كمبود بيوتين در دوران جنينى باعـث تراتوزنسيتى درمـوش هـا و همسـترها ميشـود؛

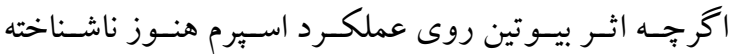
است(IV). در مطالعه اى نشان داده كه بهترين غلظت بيوتين ·llnM هmol/L هوليك اسيد بـه محيط قبـل از انجماد اسبرم انسانى موجب بهبود بِارامترهاى اسبرم شامل حيات وحر كت

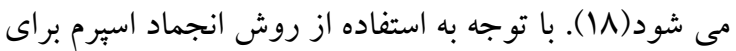
حفظ بارورى و نقش آنتى اكسيدان هـا در كاهش اثرات

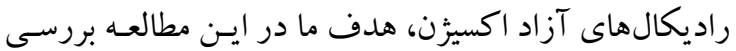
تأثير افـزودن دو مـاده اسـيد فوليكك و بيـوتين را بـر روى ״يارامترهاى اسيرم شامل حركت، حيات، شكل، تماميت غشا

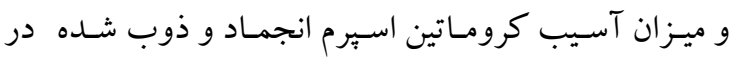

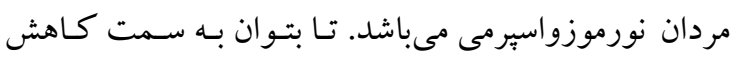
هزينه هاى مصرفى وافزايش بارورى و بقا اسبرم ها در فرايند

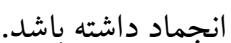

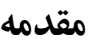
فرايند انجماد اسيرم از جمله تكنيك هاى يُ كاربرد در زمينه بارورى و نابـارورى و بانكك اسـيرم اسـت. در ايـن تكنيكك

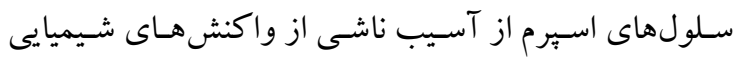

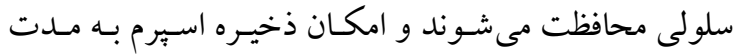

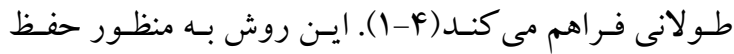

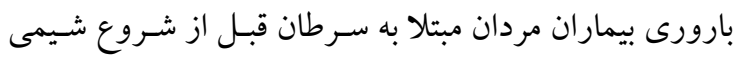

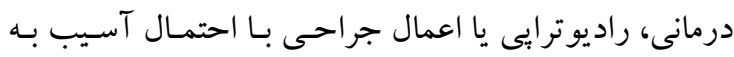
بيضه ها با احتمال نارسايى بيضهاى با مشكلات انزالى وادئ و نيسز در مردان تحت عمل جراحى واز كتومى جهت ذخيره اسـيرم

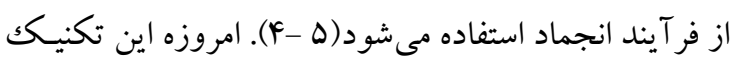

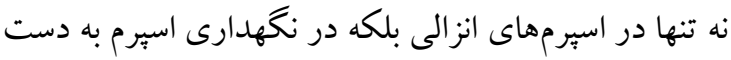

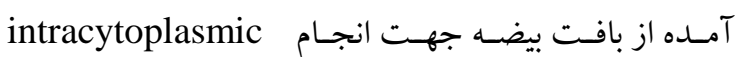
(ICSI) sperm injection

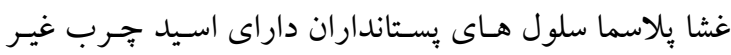

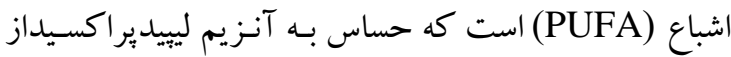

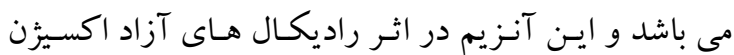
باعث تخريب ماتريكس و اختـلال عملكـرد اسـبرم (ROS) مسى شـود(Y).كامـت هـا، توليــ داخلـى راديكالهــاى آزاد

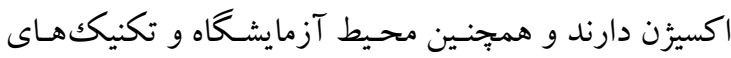
كمـك بـارورى ازجمله نـور مرئى، تر كيـب محيط كشـت،

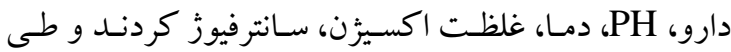
آماده سازى اسبرماتوزوآ، نيز در توليد راديكال هـاى فعـال اكسيرن (ROS) مؤثر هستند( ) - V ). عملكرد ROS يا تغيير در برو تامين اسيرم باعث افزايش حساسيت DNA اسـيرم بـهـ

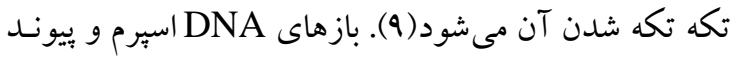

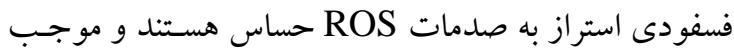
تخريب بازها، بيوستخى عرضى يـروتيين هـا و تجزيـه شـدن DNA

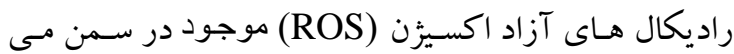

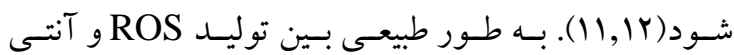
اكسيدان هـاى سـمن تعـادل نسبى ديـده مسى شـود ولى در

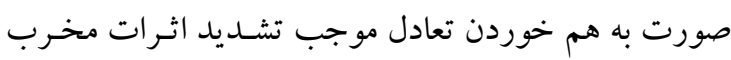

هبله علمى دانشكاه علوه بِزشكى كردستان / دوره بيست و شش / دعر و آبان م.ع|| 
شدند، اين محيط با اسيد فوليكك يا بيوتين يا هردوغنى سازى شدند. مراحل انجماد به منظورحفظ حد اكثرى قابليت و عملكرد اسبرم دركو تاهترين زمان و دقت انجام شد. ابتدا همانطوركه بيان شد، بر طبق نياز مطالعه تمامى

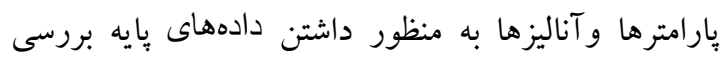

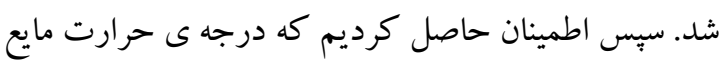
سمن و محلول فريز اسبرم برابر با دماى اتاق باشد. حجم

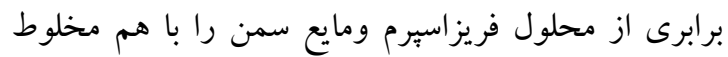
كرديم. به اينصورت كه به آرامى وقطره قطره محلول فريز

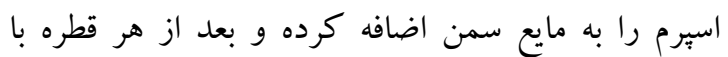

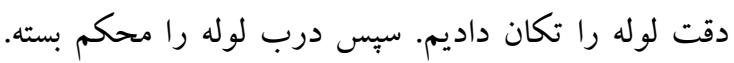

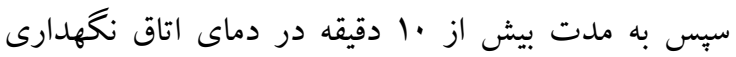

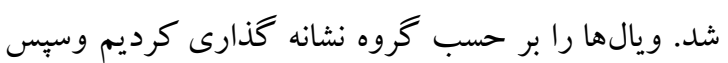
مخلوط مايع اسيرم تهيه شده را به به ويال اضافه كرديم.

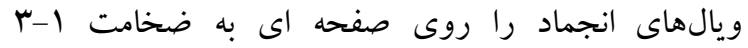
سانتيمترى كذاشته وصفحه را روى حمام نيتروز رون مايع (199-) به مدت ·r دقيقه قرار داديم. (بانجام اين مرحله و

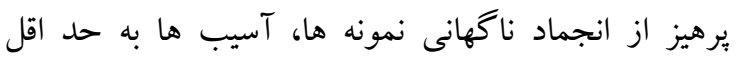
رسيد.) سبس ويال ها را داخل نيتروزن مايع فرو برديم و دردماى 199 - درجه ى سانتى گراد ذخيره كرديم. بعد از دو هفته ويال ها از تانك خارج و بالافاصله داخل ظرف دانى

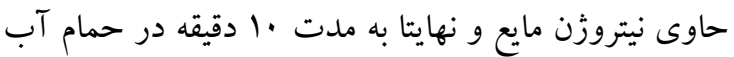

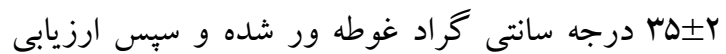
يارامترهاى اسبرم مورد ارزيابى قرار خرفتند. روش تعيين ميزان حركت، غلظت و مورفولوزى اسبرم ها:

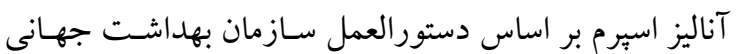
انجـام شـد. (WHO World Health Organization) تحـرك ومورفولـوزى اســرم يكى ازمهمتــين فاكتورهـا درتعيين بِتانسيل بارورى فرد مى باشد كـه بـا استفاده از نـرم افزار كامييوتر computer ارزيابى حيات اسبرم ها بارنگك آميزى ائوزين -نغروزين:

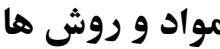
اين مطالعه از نوع كار آزمايى (experimental) آينده نخـر

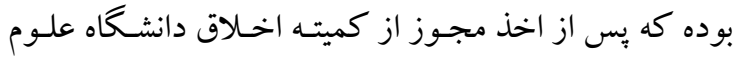

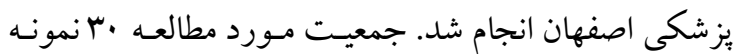

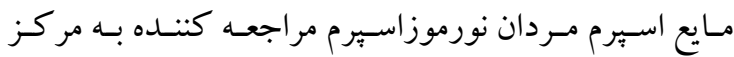
بارورى و نابارورى بيمارستان شهيد بهشتى اصفهان در سـال

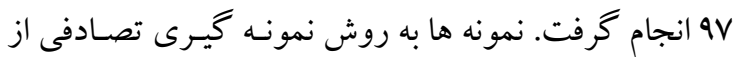

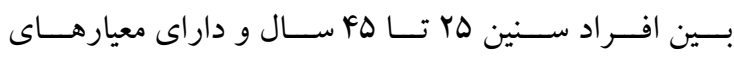

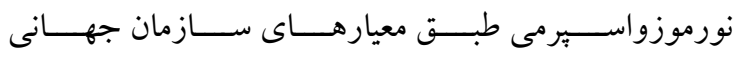

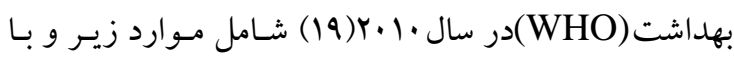

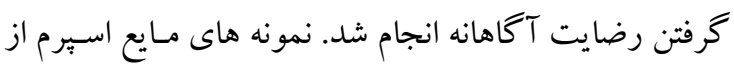

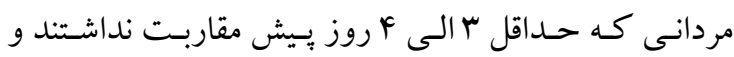
درظروف استريل گر فته شد.

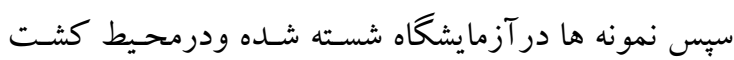

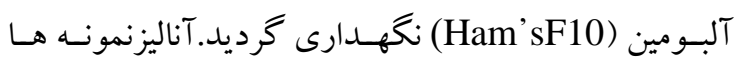

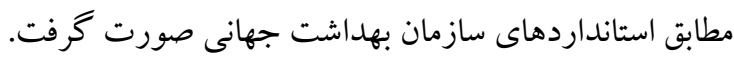
نمونه ها را به ه قسمت تقسيم كرديم و يكك قسمت آن قبـل انجماد هارامترهاى لازم شامل: غلظت، مورفولـوزى، حيـات

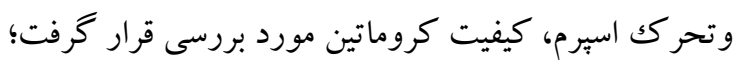

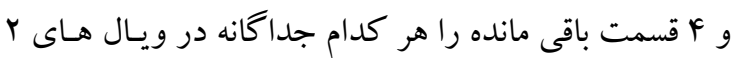
سى سى (cryovial) درجهار گروه؛ انجمـاد بـا محيط فريز

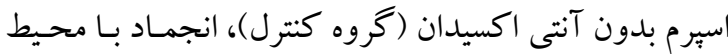
فريزاسبرم حاوى غلظmM · إبيوتين، انجماد بـامحيط فريز

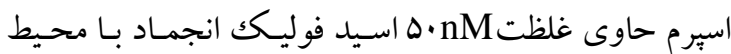
فريز اسـبرم حـاوى غلظت nM •ه اسـيد فوليكك و غلظت

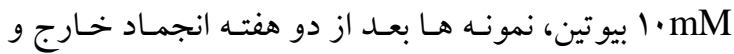
ذوب شدند ومجددا از لحاظ بارامترهاى اسبرم بررسى شد.

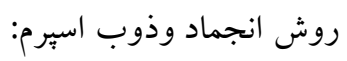

محيط فريز اسبرم انسانى، از شركت Sperm vitrolife) Freeze Solution,Vitrolife, Goteborg, خريدارى شد. فريز اسبرم با استفاده از ويالهاى Sweden) فريز r سى سى كه مراحل فريز وذوب بر اساس بروتكل vitrolife 
توسط ميكروسكوب نورى با بزر گنمايى عدسى شيئى ..1.

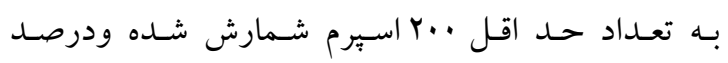

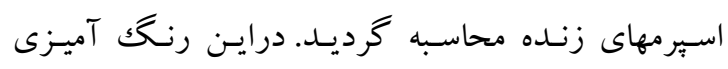

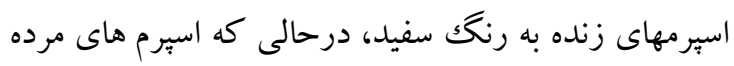

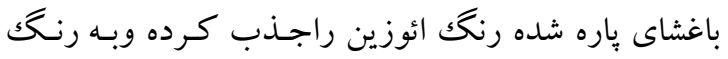

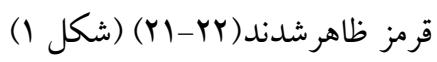

بررسى حيات اسيرم بـا رنگك آميزى ائوزين -نخـروزين

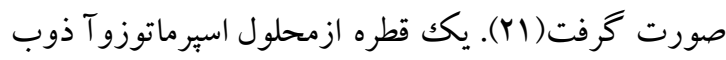

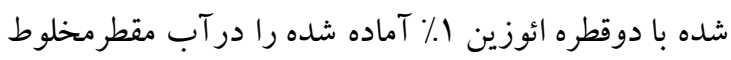

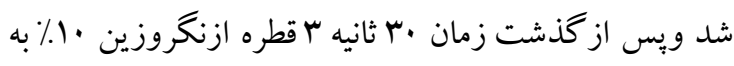

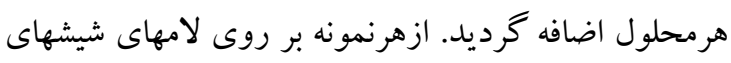

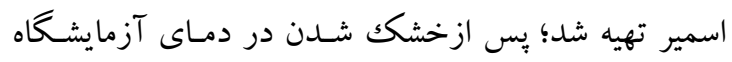

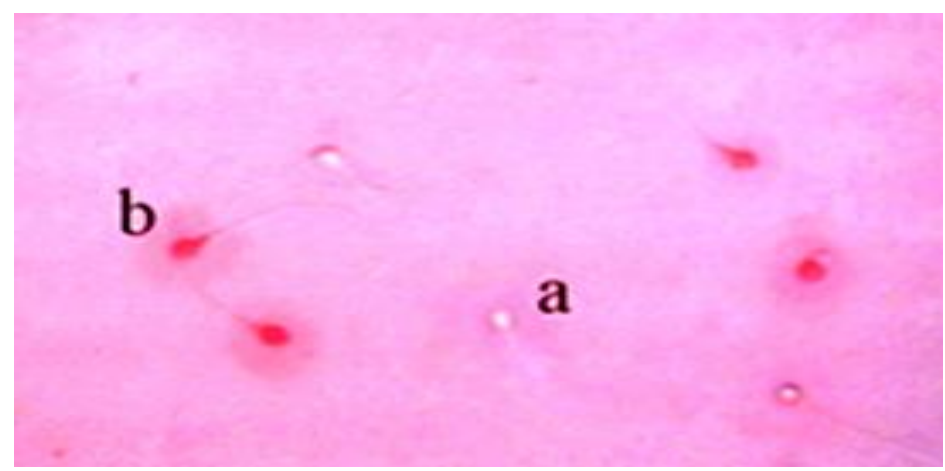

.شكل ا.رنك آميزى ائوزين-نكروزين. اسيرم هاى بدون رنك (a))، سلول زنده و اسيرم هاى قرم زرنك (b) به به عنوان سلول مرده

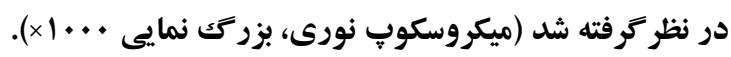

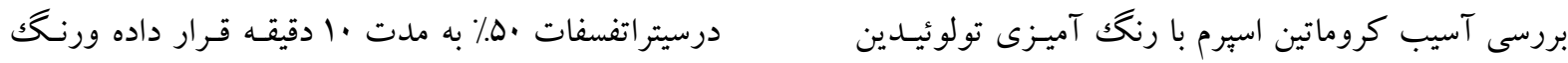

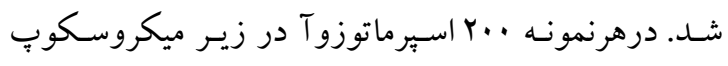
: Toluidine Blue (TB) بلو

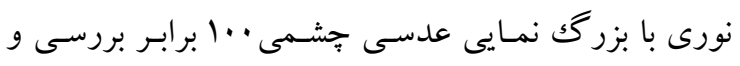
در ايـن روش رنــك آميزى، كيفيـت وكميـت تـراكم

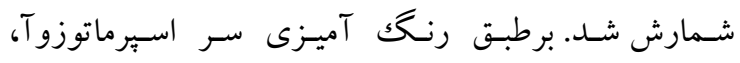

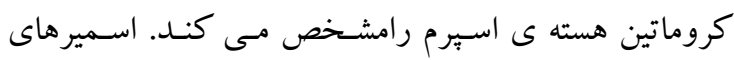

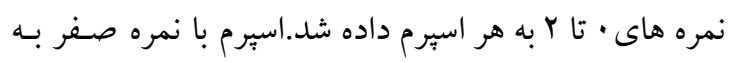

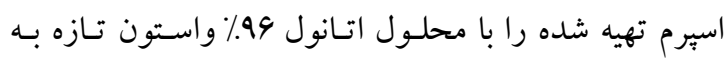

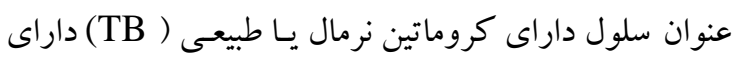

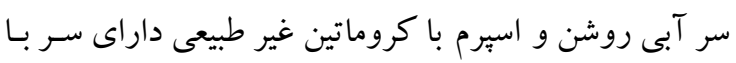

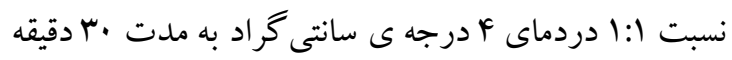

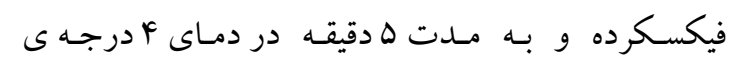

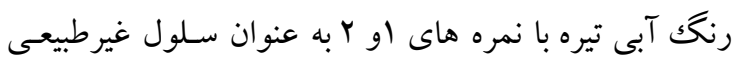
سانتى گراد در محلول / / نرمال هيدرو كلريكك اسيد انكوبـه (TB+)

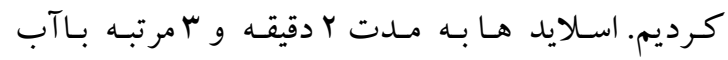

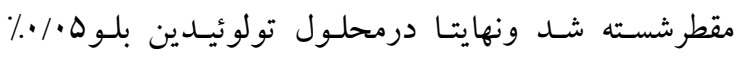

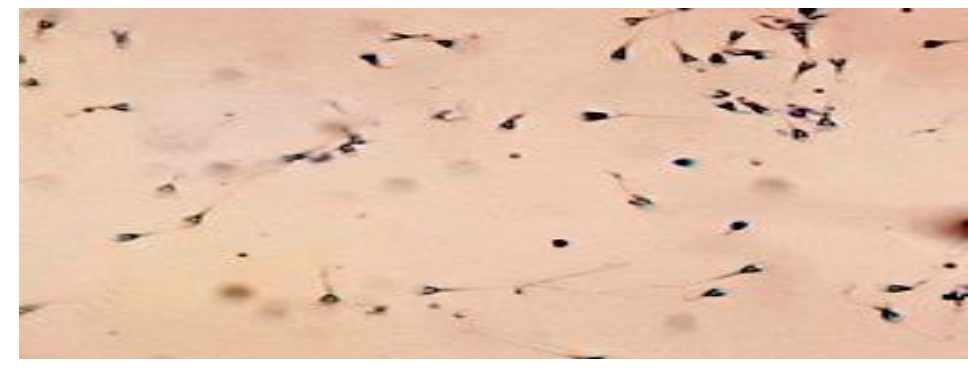

شكل r. رنك آميزى تولوئيدين بلو.: آبى روشن (كروماتين طبيعى) ا: آبى تيره (كروماتين غيرطبيعى به صورت خفيف) ז:بنفش و

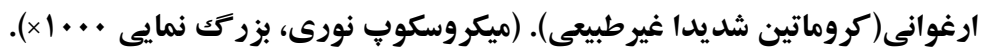


مدت ·r دقيقه قرار داديم.سبس · ا ميكروليتر از مخلوط تهيه شده روى يكك لام قرارداده و سيس روى آن لامل كذاشتيم • با استفاده از ميكروسكوبِ نورى با بزر گنمايى عدسى شيئى

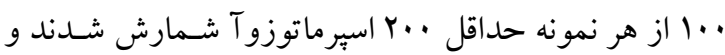
درصد اسيرم هاى متورم با دم بيיج خورده محاسبه شد.در اين روش اسيرم هاى زنده با غشا سالم، دم يبيج خـورده و متـورم واسيرم ها با غشاى سلولى تخريب شده، دم صـاف و متـورم نشده مشاهده شدند(YF)(شكل r).
بروسى تماميت غشا به روش :swelling Test) براى تهيـه محلـول ايجادكنــده تـورم در اسـيرم هسل/•گرم

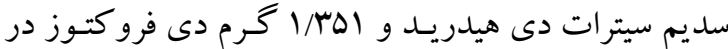

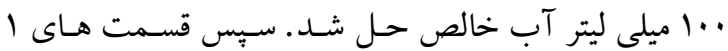
ميلى ليترى از اين محلول در انجماد با دماى منهاى ·r درجه سانتيخراد نكهدارى شد. موقع استفاده براى هر نمونه يكى از ويال هاى انجمادشده را در دماى WV درجه قـرار نمـوديم تـا

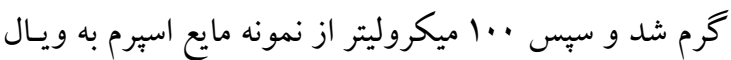
اضافه و خوب مخلوط كرديم. بعـد در دمـاى WV درجسه بــ

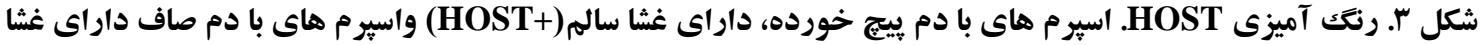

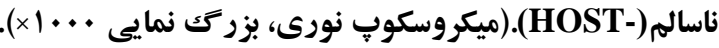

انجمـاد ايـن ارتبـاط معنـادارى بـود.در حسالى كـه بيـوتين و اسيدفوليكك باعث حفـظ حيـات و مورفولـوزى اسـبرم شـد.

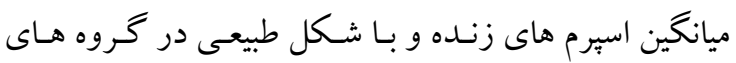

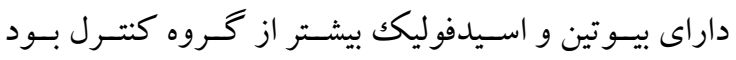

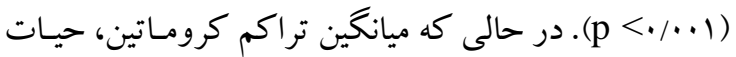

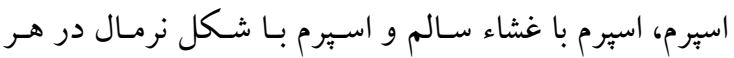
جهار كروه بعد از انجماد به طور معنـادارى كمتـر از قبـل از

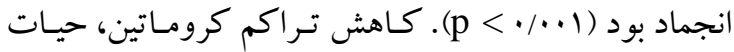

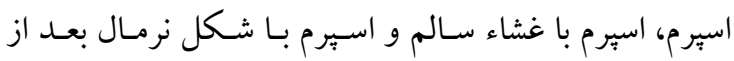

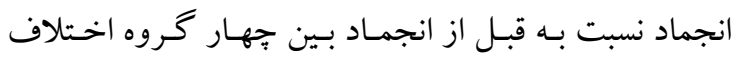

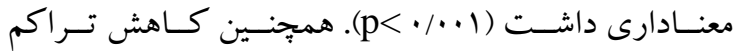
كروماتين بعد از انجماد در گروه اسيد فوليك كمتر از گروه بيو تين + اسيد فوليكك بـود، در گرووه بيوتين +اسـيد فوليكك كمتر از گروه بيوتين و در گروه بيوتين كمتر از گروه كنترل

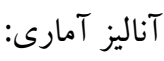

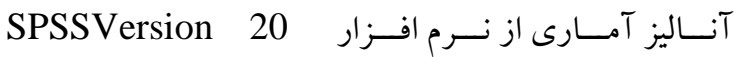
مورد تجزيه و تحليل قرار كرفت. در (Inc.,Chicago.IL) ايـن مطالعـه از آزمسون آمـارى T وابسته و آنـاليز واريـانس

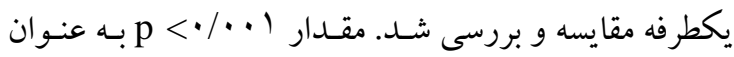
سطح معنى دارى در نظر گرفته شد. نتايج: بر اساس جدول ب-اونمودار ا، در نمونه هاى تازه و قبـل از فر آيند انجماد و ذوب، بين تـراكم غيــ طبيعى كرومـاتين و ميز ان كـاهش اســرم بـا غشـاء سـالم ارتبـاط مسـتقيم وجـود

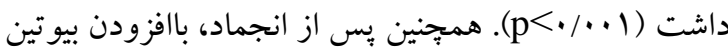
و اسيد فوليكك به محيط كشت اسيرم موجب افز ايش اسـِرم ها با تراكم كرماتين سالم و اسِرم ها با غشاء سالم داشت كه اسيدفوليكك نسبت به بيو تين موثرتر بـود و نسـبت بـه قبـل از 
جهــار گَرـروه بــه طـور معنـادارى بيشـتر از قبـل از انجمـاد بود. كاهش حيات اسبرم در كروه كنتـرل بـه طـور معنـادارى

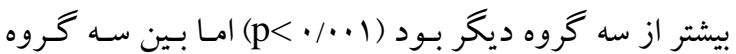
ديخر اختلاف معنادارى وجود نداشت (ه. / > p p.

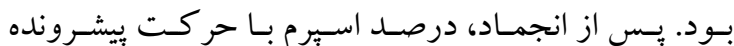
سريع (A)، حركت يُشرونده كنـد(B) و حركت درجـا (C) در هر جهار گرووه به طور معنادارى كمتـر از قبـل از انجمـاد

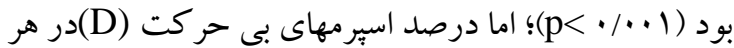

جدول ا. تراكم كروماتين، حيات اسيرم، اسيرم با غشاء سالم و اسيرم با شكل نرمال قبل و بعد از انجماد در جهار كروه:

\begin{tabular}{|c|c|c|c|c|c|c|}
\hline \multirow{3}{*}{ P-value } & \multicolumn{3}{|c|}{ بعد از انجماد } & قبل از انجماد & \multirow{3}{*}{ كروه } & \multirow{3}{*}{ متغير } \\
\hline & انحراف & ميانگين & انحر اف معيار & ميانگين & & \\
\hline & معيار & & & & & \\
\hline$<\cdot / \cdot \cdot 1$ & $9 / 1$ & $\Lambda r / v$ & $9 / \pi$ & $Q F / V$ & بيو تين & \\
\hline$<\cdot / \cdot \cdot 1$ & $1 \cdot 10$ & $\wedge \varphi / \Lambda$ & $9 / \pi$ & $Q F / V$ & بيو تين +اسيد فوليك & \\
\hline$<\cdot / \cdot \cdot 1$ & $9 / 4$ & $\Lambda 9 / \mu$ & $9 / \pi$ & $9 F / V$ & اسيد فوليكك & تــــــــــم \\
\hline$<\cdot / \cdot \cdot 1$ & $9 / 9$ & $W / F$ & $9 / \pi$ & $q F / V$ & كنترل & كروماتين \\
\hline$<\cdot / \cdot \cdot 1$ & $1 r / \cdot 1$ & $F Y / F$ & $\Lambda / 9$ & $90 / 1$ & بيوتين & \\
\hline$<\cdot / \cdot \cdot 1$ & $11 / \mathrm{V}$ & $r q / f$ & $\Lambda / 9$ & $90 / 1$ & بيوتين +اسيد فوليك & \\
\hline$<\cdot / \cdot \cdot 1$ & $9 / \Delta$ & $r V / \Delta$ & $1 / 9$ & $90 / 1$ & اسيد فوليك & حيــــــــات \\
\hline$<\cdot / \cdot \cdot 1$ & $9 / 1$ & $r Y / 9$ & $\Lambda / 9$ & $9 \Delta / 1$ & كنترل & اسيرم \\
\hline$<\cdot / \cdot 1$ & $9 / \mathrm{V}$ & $90 / \mathrm{V}$ & $\Lambda / 1$ & VQ/I & بيوتين & \\
\hline$<\cdot / \cdot \cdot 1$ & $\Lambda / F$ & $99 / 1$ & $\Lambda / 1$ & $\vee q / 1$ & بيوتين +اسيد فوليك & \\
\hline$<\cdot / \cdot \cdot 1$ & $V / q$ & $V r / \cdot r$ & $\Lambda / 1$ & $V 9 / 1$ & اسيد فوليك & درصـــــــ \\
\hline \multirow[t]{2}{*}{$<\cdot / \cdot \cdot 1$} & $1 \cdot / 4$ & $\Delta F / \Delta$ & $\Lambda / 1$ & $V 9 / 1$ & كنترل & اســـرم بـــا \\
\hline & & & & & & غشاء سالم \\
\hline$<\cdot / \cdot \cdot 1$ & $1 / 9$ & $1 / 9$ & $\cdot / A$ & $\Delta / \Delta$ & بيوتين & \\
\hline$<\cdot / \cdot \cdot 1$ & $1 / 1$ & $1 / 9$ & $\cdot / 1$ & $\Delta / \Delta$ & بيوتين +اسيد فوليك & \\
\hline$<\cdot / \cdot \cdot 1$ & $1 / \Lambda$ & $1 / V$ & $\cdot / 1$ & $\Delta / \Delta$ & اسيد فوليكك & درصـــــــ \\
\hline \multirow[t]{2}{*}{$<\cdot / \cdot \cdot 1$} & $\cdot / r$ & $\cdot 11$ & $\cdot / \Lambda$ & $\Delta / \Delta$ & كنترل & اســـرم بــــا \\
\hline & & & & & & شكل نرمال \\
\hline
\end{tabular}




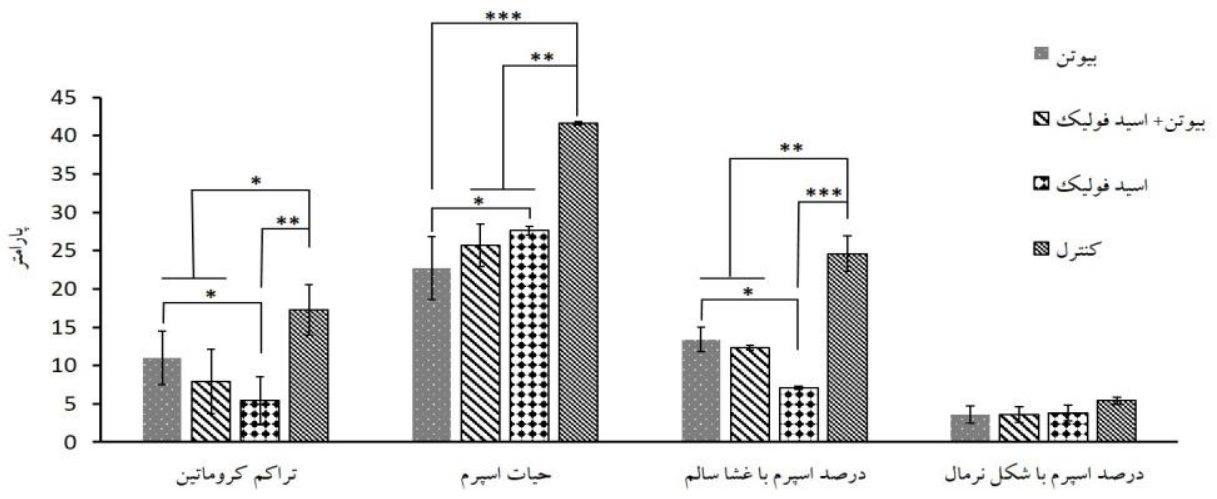

نمودار ا: كاهش تراكم كروماتين، حيات اسيرم، اسيرم با غشاء سالم و اسيرم با شكل نرمال بعدازان برانجماد نسبت به قبل ازانجماد

درجهار

جدول ז: اسيرم با حر كت يِشرونده سريع، حر كت ييشرونده كند، با حر كت درجا و بع حركت قبل و بعد از انجماد در جهار كروه.

\begin{tabular}{|c|c|c|c|c|c|c|}
\hline \multirow{3}{*}{ P-value } & \multicolumn{2}{|c|}{ بعد از انجماد } & \multicolumn{2}{|r|}{ قبل از انجماد } & \multirow{3}{*}{ كروه } & \multirow{3}{*}{ متغير } \\
\hline & انحــــــــــــ & ميانخين & انحــــــــــــ & ميانگين & & \\
\hline & 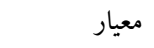 & & 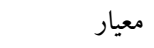 & & & \\
\hline$<\cdot / \cdot \cdot 1$ & $1 / 0$ & $1 / 9$ & $N / \cdot r$ & $r Y / r$ & بيو تين & \\
\hline \multirow[t]{2}{*}{$<\cdot / \cdot \cdot 1$} & $9 / 1$ & $F / r$ & $N / \mu$ & $r Y / r$ & بيو تين +اســـــــــيد & \\
\hline & & & & & 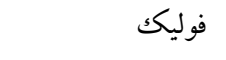 & 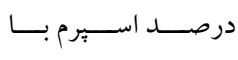 \\
\hline$<\cdot / \cdot \cdot 1$ & $1 / 9$ & $1 / V$ & $N / \cdot r$ & $r r / r$ & اسيد فوليك & حركـــت بيشــــرونده \\
\hline$<\bullet / \cdots 1$ & $\cdot / \Lambda$ & $\cdot / f$ & $N / r$ & $r Y / r$ & كنترل & سريع س \\
\hline$<\bullet / \cdots 1$ & $11 / \mathrm{V}$ & $10 / 9$ & $\Lambda / \mu$ & $F \mid / r$ & بيو تين & \\
\hline \multirow[t]{2}{*}{$<\cdot / \cdot \cdot 1$} & $1 \% / 0$ & $10 / \Delta$ & $\Lambda / \mu$ & $F \mid / r$ & 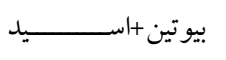 & \\
\hline & & & & & فوليك & درصــــد اســـرم بـــــا \\
\hline$<\cdot / \cdot \cdot 1$ & $\Lambda / 9$ & $\mid r / F$ & $\Lambda / \mu$ & $F I / r$ & اسيد فوليك & حركت بيشرونده كند \\
\hline$<\bullet / \cdot \bullet 1$ & $\mid r / Y$ & IV/A & $\Lambda / \mu$ & $F \mid / r$ & كنترل & \\
\hline$<\bullet / \cdot 1$ & $\Delta / \mu$ & $9 / 9$ & $r / r$ & $r r / \Delta$ & بيو تين & \\
\hline \multirow[t]{2}{*}{$<\cdot / \cdot \cdot 1$} & $f / f$ & $V / f$ & $f / \mu$ & $r r / D$ & بيو تين +اســــــــــد & \\
\hline & & & & & 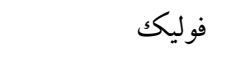 & درصــــد اســـرم بـــــا \\
\hline$<\cdot / \cdot \cdot 1$ & $9 / \cdot 1$ & $1 \cdot 11$ & $f / r$ & $r \mu / \Delta$ & اسيد فوليك & حركت درجا \\
\hline$<\cdot / \cdot \cdot 1$ & $f / F$ & $V / I$ & $f / \mu$ & $r \mu / D$ & كنترل & \\
\hline$<\cdot / \cdot \cdot 1$ & $19 / 4$ & $V Y / \Lambda$ & $\Lambda / \mathcal{F}$ & $1 Y / 9$ & بيو تين & \\
\hline \multirow[t]{2}{*}{$<\cdot / \cdot \cdot 1$} & $r \cdot / 9$ & $V Y / V$ & $\Lambda / F$ & $1 Y / 9$ & بيو تين +اســــــــــد & \\
\hline & & & & & فوليك & درصــــ اســـرم بــى \\
\hline$<\cdot / \cdot \cdot 1$ & $10 / 4$ & $V \Delta / q$ & $\Lambda / \mathcal{F}$ & $1 Y / 9$ & اسيد فوليك & حركت \\
\hline$<\cdot / \cdot \cdot 1$ & $14 / 9$ & $V F / V$ & $\Lambda / F$ & $1 Y / 9$ & كنترل & \\
\hline
\end{tabular}


جدول r. كاهش ٪ اسيرم با حر كت A، حر كت B و حر كت Cو افزايش ٪ اسيرم D بعد از انجماد نسبت به قبل از انجماد در جهار كروه:

\begin{tabular}{|c|c|c|c|c|}
\hline P-value & انحر اف معيار & ميانگين & 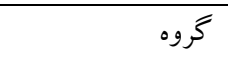 & 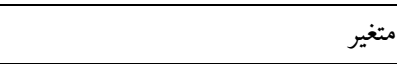 \\
\hline \multirow{4}{*}{ r } & $N / r$ & $r \cdot / 4$ & بيوتين & \\
\hline & $1 / 4$ & $M / \cdot r$ & بيو تين+اسيد فوليك & \\
\hline & $\mathrm{V} / \mathrm{V}$ & $r \cdot / V$ & اسيد فوليك & كـاهش درصـــ اسـبرم بــاـ حركـت \\
\hline & N/I & $r Y / q$ & 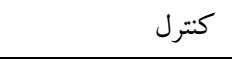 & بيشرونده سريع \\
\hline \multirow{4}{*}{.194} & $10 / 9$ & $r \Delta / V$ & 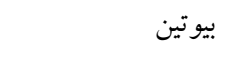 & \\
\hline & $\mid V / I$ & $r \Delta / \Delta$ & بيو تين+اسيد فوليكك & \\
\hline & $\mid r / 1$ & YN/9 & اسيد فوليك & كـاهش درصـــ اسـيرم بــا حركـت \\
\hline & $1 \% / r$ & $r r / \Delta$ & 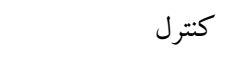 & بيشرونده كند \\
\hline \multirow{4}{*}{$\cdot / r$} & $9 / 9$ & $10 / 9$ & 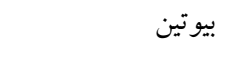 & \\
\hline & $\mathrm{V} / \mathrm{I}$ & 1911 & بيو تين+|سيد فوليكك & \\
\hline & $9 / 9$ & $1 r / 4$ & اسيد فوليك & كاهش درصد اسيرم با حر كت درجا \\
\hline & $\Delta / 9$ & $19 / 4$ & 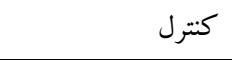 & \\
\hline \multirow{4}{*}{$\cdot / \wedge 9$} & $19 / 9$ & $\Delta q / q$ & 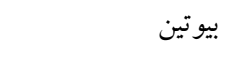 & \\
\hline & $r Y / 9$ & $\Delta Q / 9$ & بيو تين+|سيد فوليك & \\
\hline & $\mathrm{IV} / \mathrm{r}$ & $G T / V$ & 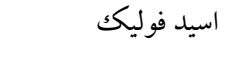 & افزايش درصد اسيرم بى حركت \\
\hline & $1 F / \Lambda$ & $91 / 1$ & 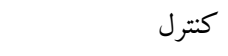 & \\
\hline
\end{tabular}

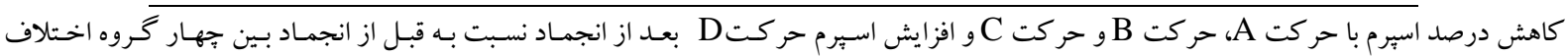

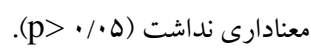

هم: (YO) بحث

فولات موجب افزايش آسيب DNA مى شود (Y) مكن). در مطالعات ديخر، اثر مثبت كاربرد آنتى اكسيدان در محيط

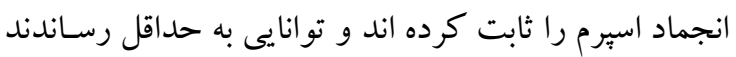

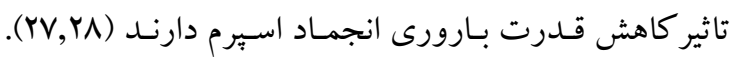

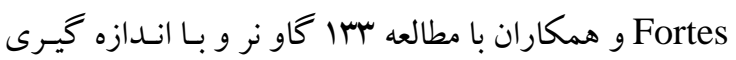

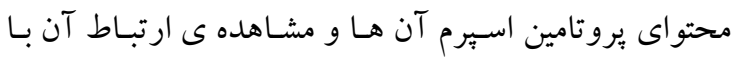

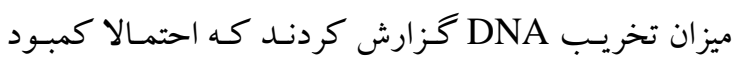

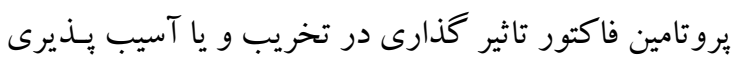
DNA اين سلول ها مى باشد (Y9).

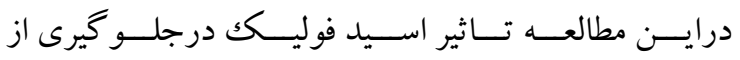

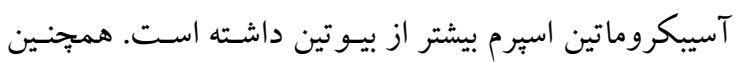

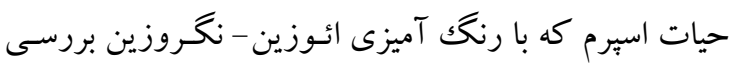

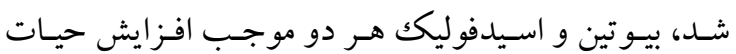
در مطالعه حاضر تاثير بيوتين و اسيد فوليكو تر كيـب هـر دو

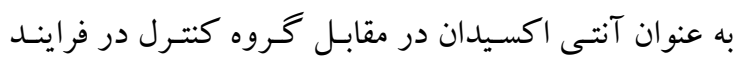

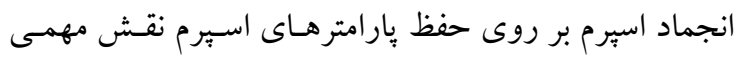

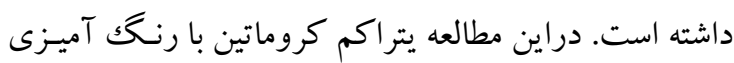
تولوئيدن بلو سنجيده و مشـاهده شد،اسيد فوليكـو بيـوتين و

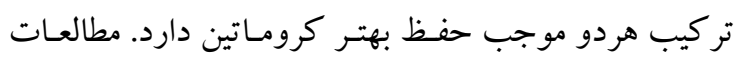

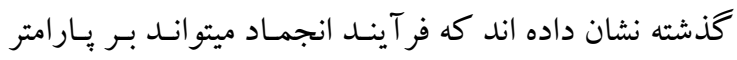

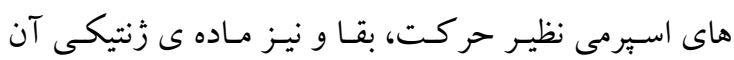

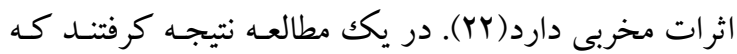

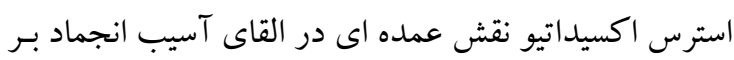

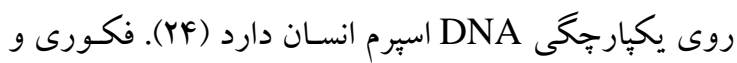

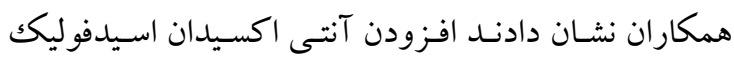
بهبود بِارامترهاى حركتى در اسبرم رت را بـه همـراه داشـت 
ارزيابى وضعيت تراكم كرومـاتين بـا TB و تماميـت غشـا اسيرم با روش HOST نشان دهنده حفظ يتانسيل بـارورى فرد باشد. تسـ HOST ميتوانـد نقشى حيـاتى در ارزيابى

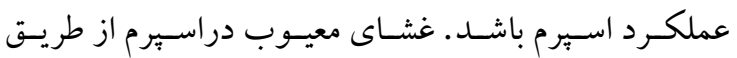
آزمايش HOST تشخيص داده مى شود كه ممكن است در برد

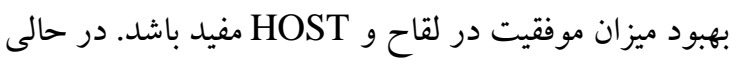

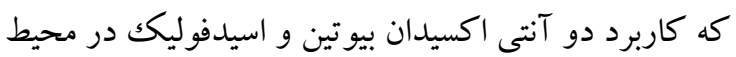
انجماد اسيرم قبل از انجمـاد و ذوب، يـا بـه عبـارت بهتر در نمونه هاى در معرض آسيب، با انجام رنگك آميزى نسبتا ساده

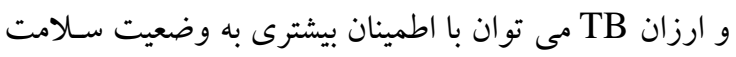

$$
\text { كروماتين اسبرم يى برد. }
$$

\section{نتيجه كيرى} بيوتين و اسيد فوليكك اثر محافظتى روى كيفيـت كرومـاتين، غشائ سالم، حيات اسبرم و نقـش مهمى در حفـظ بـارامتر هاى اسبرم در فرايند انجماد اسبرم و تكنيك هاى وابسته بـهـ آن داشته باشد، اما براى تأييد اين اثر تحقيقات بيشترى لازم

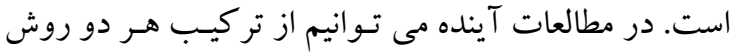
خوراكى و افزودن به محيط انجماد استفاده كنيم. همجنسين مى توان تاثير اين دو ماده را در مردان با مشكل بـارورى نيز

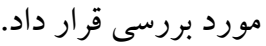

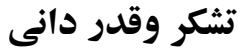

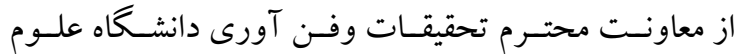
يزشكى اصفهان به دليل حمايت از اين طرح سياسعنداريم.

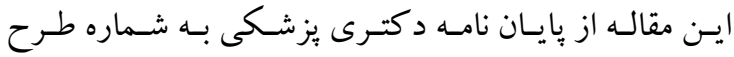

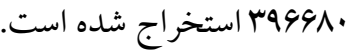

اسبرم شدند ولى تفاوتى بين سه گروه بيوتين،اسيدفوليك و

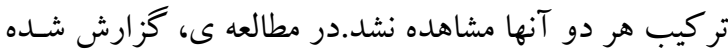
كه بيوتين موجب افزايش حيات وبهبودحر كت اسبرم نسبت

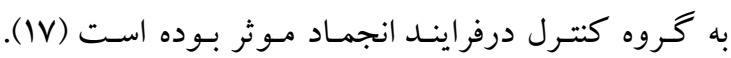
مطالعات قبلى اثر مثبت كاربرد آنتى اكسـيدان، اسـيدفوليكك به محيط انجماد قبل از فر آيند انجماد اسبرم، درصد حيـات التيات

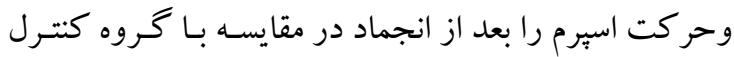

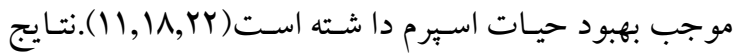
يُزوهش هـاى انجـام شــه در شـــايطى كـه بـر ميزان تـراكم

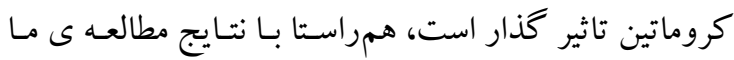
مىباشد. نتايج مطالعه ى ديخر، تاثير بنتو كسى فيلين (ويتامين ب ه) روى تماميت غشـا اسيرم بـا روش HOST در فراينـد فريز

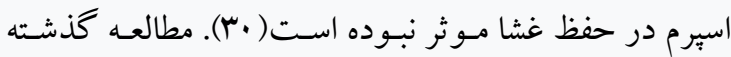
نشان داد كـه تسـت تـورم هييو اسـمزى ابزارى مهـم بـراى ارزيابى ميزان آسيب غشايى ناشى از سيخار كشيدن است در مردان نابارورى(آ).در مطالعه حاضر اثر مثبـت كـاربرد دو

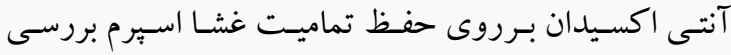
كرديــابيوتين و اسـيد فوليـك هـر دو در حفـظ غشـا مـوثر بودنــد و تـاثير اسـيد فوليكك بيشستر از بيـوتين در حركـت و و كيفيت اسيرم بوده است.همر استا با اين نتايج، در يك مطالعه ، درمان با اسيد فوليكك، موجـب افزايش حركت وتعـداد سلول هاى اسبرم نرمال نسبت به گروه كنترل شد(YM).

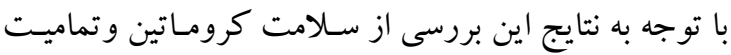

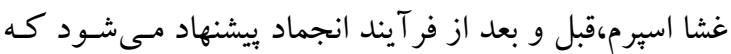
تراكم غير طبيعى كروماتين اسبرم مسى توانـد يكى از دلايـلـ حساسيت بيشتر تماميت غشا اسبرم آن نسبت به آسيب باشد. بـه نظـــ مسىرســ در مـردان نورموزواسـيرمى قبـل از فريـز،

منابع

1.Oberoi B, Kumar S, Talwar P. Study of human sperm motility post cryopreservation.. Med J Armed Forces India 2014;70(4):349-53.

2. Verza Jr S, Feijo CM, Esteves SC. Resistance of human spermatozoa to cryoinjury in repeated cycles of thaw-refreezing. Int Braz J Urol. 2009;35(5):581-91. 
3.Sa-Ardrit M, Saikhun J, Thongtip N, Damyang M, Mahasawangkul S, Angkawanish T, et al. Ultra-structural alterations of frozen-thawed Asian elephant (Elephas maximus) spermatozoa. Int J Androl 2006; 29(2): 346-52.

4.NaeiniZK,BafraniHH,Nikzad.Evaluation of ebselen supplementationon cryopreservation medium in human semen. Iran J Reprod Med. 2014;12(4):24.

5. Golshan-Iranpour F, Zamani Rarani F, Dashti GR. Effect of chromatin condensation on frozen-thawed sperm DNA integrity in normozoospermic men. SJKU 2019;24(3):34-42.

6.Soltanpour F, Moghaddam G, Asadpour R, Rafat SA. Effect of Antioxidant combinations on sperm quality of cross breed rams during liquid storage. Int $\mathbf{J}$ of Adv. Biological and Biomed Res. 2014;2(3):732-40.

7. Amidi F, Pazhohan A, Nashtaei MS, Khodarahmian M, Nekoonam S. The role of antioxidants in sperm freezing: a review. Cell and tissue banking. 2016;17(4):745-56.

8.Toghiani S, Dashti GR, Roudbari NH, Rouzbehani S, Monajemi R. Lithium carbonate inducing disorders in three parameters of rat sperm. Adv. Biomed Res 2013;2 :55.

9.Hamilton T, Assumpcao M. Sperm DNA fragmentation: Causes and identification. Zygote.2020;28(1):1-8.

10.Hosen MB, Islam MR, Begum F, Kabir Y, Howlader MZ. Oxidative stress induced sperm DNA damage, a possible reason for male infertility. Iran J Reprod Med 2015; 13(9): 525-32.

11. Sadeghi Z, Ishaqi S, Dashti GR. The effect of folic acid and nicotinic acid on malondialdehyde levels of semen in oligospermia men after cryopreservation. J Isfahan Med Sch. 2021; 38(603): 921-928. (In persian)

12. Hosseini J, Mamaghani AM, Hosseinifar H, Gilani MAS, Dadkhah F, Sepidarkish M. The influence of ginger (Zingiber officinale) on human sperm quality and DNA fragmentation A double-blind randomized clinical trial. Int J of Reprod BioMed. 2016;14(8):533.

13. Iranpour FG, Fazelian K, Dashti GR (2017) Thymoquinone as a natural spermostatic substance in reproductive medicine: an experimental study. Int J Reprod Biomed.2017; 15:641.

14. Ghasemi N,Dashti GhR,Amoozgar F,Vaez SA.Effect of cholesterol, iron and vitamin E on protamine deficiency and DNA fragmentation of male rabbit sperm. J Isfahan Med Sch.2014;31(259):1769-78

15. Toghiani SH,Hayati N,Dashti GH,Rouzbehani SH.The effects of vitamin C and menthone on acyclovir induced DNA damage in rat spermatozoa:An experimental study.Int $\mathbf{J}$ Reprod BioMed.2018;16(11):703-710.

16. Toghiani S, Dashti GR, Roudbari NH, Roozbehani S.Effect of ascorbic acid and menthone on the caspase 3 in the sperm cells of acyclovir treated rats. Acta Medica .2016,32:1213

17. Kalthur G, Salian SR, Keyvanifard F, Sreedharan S, Thomas JS, Kumar P, et al. Supplementation of biotin to sperm preparation medium increases the motility and longevity in cryopreserved human spermatozoa. J of Assisted Reprod and Genetics.2012;29(7):631-5. 18. Khamsuk K, Sinawat S, Seejorn K, Pongsritasana T, Sukkasame S. The Effect of Folic Acid on Post-thaw Quality of Human Spermatozoa. Sri Nagarind Med J. 2014;29(4):141-5.

19. Cooper TG, Noonan E, Von Eckardstein S, Auger J, Baker H, Behre HM, et al.World Health Organization reference values for human semen characteristics. Human Reprod Update. 2010; 16(3):231-45.

20.Sadeghnejad N, Dashti GR, Zolfaghari B, Baghazadeh S, Golshan-Iranpour F. Effects of high doses of hydroalcoholic extract of nigella sativa on sperm motility and apoptosis innormozoospermic men. J Isfahan Med Sch. 2016; 34(381): 470-7. (In persian) 
وعا بررسى تاثير بيوتين و اسيد فوليك بر ...

21.Fazelian Kh, Dashti Gh, Golshan-Iranpour F, Baghazadeh Sh. Effect of low doses of exogenous thymoquinone on sperm motility and viability of normozoospermic men. J Isfahan Med Sch 2014; 32(287): 776-83(In persian)

22. Rarani F.Z, Golshan-Iranpour F, Dashti G.R. Correlation between sperm motility and sperm chromatin/DNAdamage before and after cryopreservation and the effect of folic acid and nicotinic acid on post-thaw sperm quality in normozoospermic men. Cell Tissue Bank. 2019;20(3):367-378.

23. Rahiminia T, Hosseini A, Anvari M, Ghasemi-Esmailabad S,Talebi AR. Modern human sperm freezing: effect on DNA, chromatin and acrosome integrity Taiwanese. J Obstet Gynecol. 2017;56: 472-476.

24.Ramu S, Jeyendran RS. The hypo-osmotic swelling test for evaluation of sperm membrane integrity. Methods Mol Biol.2013;927:21-5.

25. Pietrzik K, Bailey L, Shane B. Folic acid and L-5-methyltetrahydrofolate: comparison of clinical pharmacokinetics and pharmacodynamics. Clin Pharmacokinet. 2010;49(8):535-48.

26.Boxmeer JC, Smit M, Utomo E, Romijn JC, Eijkemans MJ, Lindemans J, Laven JS, Macklon NS, Steegers EA, Steegers-Theunissen RP. Low folate in seminal plasma is associated with increased sperm DNA damage. Fertil steril. 2009 Aug 1;92(2):548-56.

27. Mangoli E, Talebi AR, Anvari M, Taheri F, Vatanparast M, Rahiminia T, Hosseini A. Vitamin $\mathrm{C}$ attenuates negative effects of vitrification on sperm parameters, chromatin quality, apoptosis and acrosome reaction in neat and prepared normozoospermic samples. Taiwan $\mathbf{J}$ Obstet Gynecol. 2018;57(2):200-204.

28. Aghaz F, Khazaei M, Vaisi-Raygani A, Bakhtiyari M. Cryoprotective effect of sericin supplementation in freezing and thawing media on outcome of cryopreservation in human sperm. Aging Male.2018;19:1-8.

29.Fortes MR, Satake N, Corbet DH, Corbet NJ, Burns BM, Moore SS, Boe-Hansen GB. Sperm protamine deficiency correlates with sperm DNA damage in B os indicus bulls. Andrology. 2014;2(3):370-8.

30.Stanic P, Sonicki Z, Suchanek E. Effect of pentoxifylline on motility and membrane integrity of cryopreserved human spermatozoa. Int J of Andrology. 2002;25(3):186-90.

31.Sreenivasa G, Prasad DRM, Malini SSN. Evaluating the Functional Status of Spermatozoa in Smokers by Using Hypo-Osmotic Swelling Test. Asia Pac J Med Toxicol. 2016;5: 83-7.

32. Ghadhban R.F, Alwan N.A. The Role of Folic Acid on Some Physiological Parameters and Efficiency of Sperm in Male Rabbits. Sys Rev Pharm .2020;11(9):1003-1007. 